
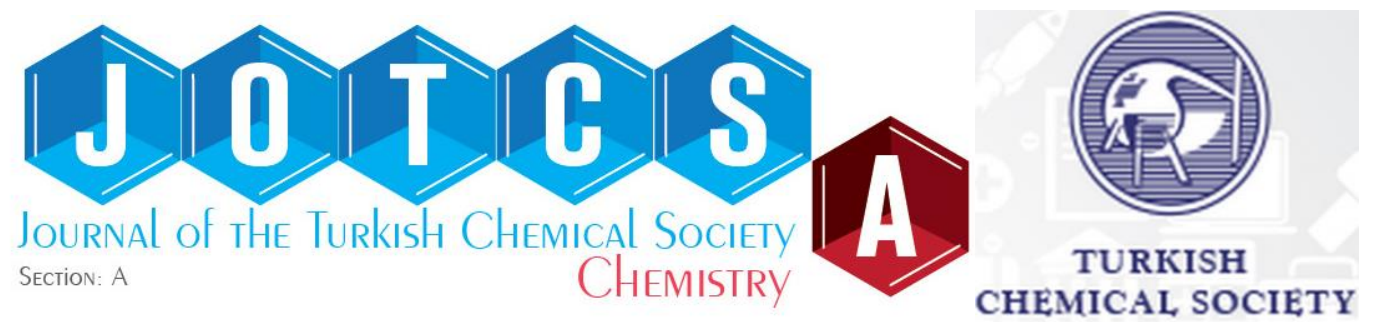

\title{
Mineralization of Hydrochlorothiazide using Hydrogen Peroxide in Subcritical Water
}

\author{
Erdal Yabalak*, Özkan Görmez ${ }^{1}$, Yahya Nural2* \\ ${ }^{1}$ University of Mersin, Faculty of Arts and Science, Department of Chemistry, TR-33343, Mersin, Turkey. \\ 'University of Mersin, Faculty of Pharmacy, Department of Analytical Chemistry, TR-33169, Mersin, Turkey.
}

Abstract: In this paper, we investigated the mineralization of hydrochlorothiazide, a diuretic drug which is used for the treatment of hypertension, using $\mathrm{H}_{2} \mathrm{O}_{2}$ as the oxidizing agent in subcritical water as a medium. Response surface methodology was applied to optimize experimental parameters such as temperature, treatment time, and concentration of the oxidizing agent. The highest TOC removal was obtained as $85.22 \%$ in 147.3 minutes of treatment time at $403 \mathrm{~K}$ using $80 \mathrm{mM}$ of hydrogen peroxide. The reliability of the performed method was evaluated by ANOVA and the theoretical equation of TOC removal of hydrochlorothiazide was proposed. $F$ and $p$ values of the model were determined as 62.88 and lower than 0.0001 , respectively.

Keywords: Hydrochlorothiazide, Degradation, Subcritical water, Hydrogen peroxide, Response surface methodology.

Submitted: August 01, 2018. Accepted: September 18, 2018.

Cite this: Yabalak E, Görmez Ö, Nural Y. Mineralization of Hydrochlorothiazide using Hydrogen Peroxide in Subcritical Water. JOTCSA. 2018;5(3):1135-44.

DOI: http://dx.doi.org/10.18596/jotcsa.449979.

*Corresponding authors. E-mail: Erdal Yabalak: yabalakerdal@gmail.com and Yahya Nural: ynural1805@yahoo.com.

\section{INTRODUCTION}

Pharmaceuticals are released to the environment during the production, storage, and postconsumption phases. Their damage to the environment, hence their damage to living systems, may be restrained by considering their environmental fate. For this reason, a large number of studies have been carried out on identification of degradation product of the pharmaceuticals and how to release them to the environment in a harmless manner (1-5). In this context, it is known that many methods have been developed to convert pharmaceuticals into harmless or less harmful species, thus safely releasing them into the environment. One of these methods is degradation of the pharmaceuticals using various chemicals in a variety of media (2). Yabalak et al. (6-9) have used hydrogen peroxide in subcritical water medium for degradation of various drugs such as propham, ticarcillin, paracetamol and oxacillin. Turabik et al. (10), have performed oxidative degradation of imidacloprid by electrochemical advanced oxidation. Hasan et al (11), have carried out degradation of sulfisoxazole on pure $\mathrm{TiO}_{2}$ under visible light irradiation. Furthermore, Giahi (12) has carried out photodegradation of diclofenac sodium by addition of a small amount of $\mathrm{K}_{2} \mathrm{~S}_{2} \mathrm{O}_{8}$ in the medium and $\mathrm{Ji}$ et al. (13) have carried out degradation of sulfaquinoxaline by a ferrous ion-activated peroxymonosulfate oxidation process.

Hydrochlorothiazide (abbreviated as HCT, 6chloro-3,4-dihydro-2H-1,2,4-benzothiadiazine-7sulfonamide 1,1-dioxide, Figure 1 ) belongs to the class of thiazides and is mainly used as a diuretic as well as for the treatment of hypertension, and symptomatic edema $(14,15)$. However, it is reported that HCT is one the most ubiquitous contaminants in the sewage and river waters in some countries (16) such as Serbia (17) and Spain (4). There are various studies in the literature related to the degradation of HCT using different methods. Real et al. (18) have reported the degradation of HCT in different media via oxidation by means of UV radiation, Fenton's 
reagent and ozone. Mahajan et al. (19) have performed the degradation of HCT under hydrolytic, oxidative, photolytic and thermal stress conditions, and have characterized its degradation products using high performance liquid chromatography. In another study, Márquez et al. (20) have carried out the degradation of HCT and some other drugs in ultrapure water and in water from a municipal wastewater treatment plant, by various oxidation methods such as conventional ozonation, photolytic ozonation, $\mathrm{TiO}_{2}$ catalytic ozonation, etc. Contreras et al. (21) have reported the degradation of HCT via electrochemical oxidation. Moreover, there are several other studies in the literature for the degradation of HCT using similar degradation methods (22-25). However, to the best of our knowledge, there is not any study related to the degradation of HCT using hydrogen peroxide in subcritical water medium.

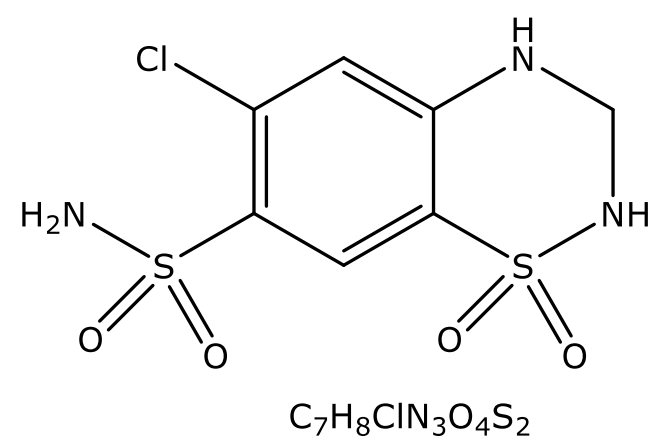

Figure 1: Chemical structure of HCT.

Subcritical water is defined as water which is heated to a temperature range of $373 \mathrm{~K}-647 \mathrm{~K}$ and pressurized to keep it in the liquid state in this temperature range (26). It is known that subcritical water has been used in many processes such as oxidation, extraction $(9,26)$, solubility (27) and in organic synthesis (28), due to its important properties such as being a green solvent, good availability, cheapness, and having an easily adjustable polarity (29). Subcritical water has been widely used in oxidation processes, because during the subcritical water oxidation process hydroxyl radicals and active oxygen species originate at elevated temperatures and pressures without the addition of an oxidizing agent. Furthermore, if an oxidizing agent such as oxygen, permanganate, hydrogen peroxide, etc., is added to the subcritical medium, this treatment can assist the process to efficiently oxidize various potential pollutants which are difficult to oxidize with conventional methods (8, $30,31)$. Subcritical water medium favors the formation of free hydroxyl radicals in the presence of hydrogen peroxide. Hydroxyl radical is a reactive species and attacks to target molecule and provides its mineralization. This feature of subcritical water medium and hydrogen peroxide system indicates that it is a superior method comparing to the conventional methods (7).
Response surface methodology (RSM) is one of the most widely used and accepted chemometric methods. RSM is a useful statistical-based method which is used to optimize the process parameters with a limited number of experiments from many varieties. RSM can also be used to analyze the effects of several independent variables on the response, evaluating the individual and interaction effects of independent variables and to evaluate the performance of a system and the interactions between the experimental parameters in the multivariable chemical process $(6,32,33)$.

In the present study, the degradation of HCT using hydrogen peroxide as oxidizing agent in subcritical water medium is reported. The optimal experimental parameters such as temperature, treatment time and concentration of oxidizing agent, and the theoretical maximum total organic carbon (TOC) removal rates were determined using RSM.

\section{EXPERIMENTAL SECTION}

\section{Materials}

$\mathrm{HCT}$ and $\mathrm{H}_{2} \mathrm{O}_{2}$ were supplied from Sigma-Aldrich (St. Louis, MO, USA). $\mathrm{N}_{2}$ gas was obtained from Linde gas (Turkey). Ultra-pure water $(18 \mathrm{M} \Omega . \mathrm{cm}$, $25^{\circ} \mathrm{C}$ ) was prepared by using Millipore Milli-Q Advantage A10 apparatus (Darmstadt, Germany). $1000 \mathrm{mg} / \mathrm{L}$ TOC standard solution was obtained from Merck (Darmstadt, Germany).

\section{Degradation method}

The experimental set-up (a home-made reactor, heater with a magnetic stirrer and digital thermometer), which is reported in a previous paper (7), was used to carry out the degradation experiments. Preliminary experiments were done to determine treatment conditions. Further, the central composite design (CCD) method, which is one of the design methods of the RSM, was used to design the experimental conditions. The treatment conditions were lying in the temperature range of $352.5 \mathrm{~K}-453.5 \mathrm{~K}$, concentration of oxidizing agent range of 12.7 $\mathrm{mM}-147.3 \mathrm{mM}$, and treatment time range of $12.7 \mathrm{~min}-147.3 \mathrm{~min}$ as demonstrated in Table 1. The degradation method, which is briefly summarized below, was performed according to Yabalak, 2018 (7). A specific amount of HCT was dissolved in ultra-pure water to prepare $50 \mathrm{ppm}$ of stock aqueous solution of HCT. $150 \mathrm{~mL}$ of freshly prepared stock solution was placed in the reactor. In each experiment, a certain amount of $\mathrm{H}_{2} \mathrm{O}_{2}$, which is displayed in Table 2 , was added into the reactor. The reactor was closed, screwed and pressurized to 30 bar by using $\mathrm{N}_{2}$ gas. The reactor was heated to the target temperature according to the experimental design given in Table 2. After keeping a constant temperature during the treatment time, the reactor was cooled down to the room temperature, depressurized and opened. Finally, at the end of the treatment 
time, $20 \mathrm{~mL}$ of the treated sample was collected and stored at $277 \mathrm{~K}$ for TOC analysis.

\section{TOC method}

TOC analysis is a common and practical application used to assess the quality of waters by determining its organic content (34). TOC values of the stock solution and treated samples were determined by using a TOC-L analyzer with an ASI-L autosampler (Shimadzu). TOC removal percentages were calculated according to the equation given in the previous work (7).

\section{CCD modeling}

RSM, which is a statistical tool that consists of mathematical techniques, enables the optimization of the process (6). CCD is one of the several RSM models and it provides the explanation of the correlation between the experimental variables and responses by designing experiments $(7,35)$. It is based on full factorial or fractional factorial second-order designs and it consists of factorial, central, and axial points in the experimental region $(9,36)$.
Design Expert 9.0.6.2 was used to design the three-factor experimental matrix. Table 1 demonstrates the design of the experimental factors along with their coded levels. Independent variables such as temperature, concentration of oxidizing agent, $\mathrm{H}_{2} \mathrm{O}_{2}$, and treatment time were coded as $x_{1}, x_{2}$, and $x_{3}$, respectively. 20 runs from the experimental region were performed and experimental and predicted results of TOC removal efficiency of all runs were displayed in Table 2. Furthermore, the correlation between response and independent variables was enlightened according to the obtained quadratic equation (Eq 1 ) of the model. In this equation, $Y$ indicates the response (TOC removal percentage), where $x_{1}, x_{2}$, and $x_{3}$ depicts the coded independent variables, $x_{1}{ }^{2}, x_{2}{ }^{2}$, and $x_{3}{ }^{2}$ represent the square effects. $x_{1} x_{2}, x_{1} x_{3}$, and $x_{2} x_{3}$ symbolize interaction effects. The coefficients of linear and quadratic terms indicate their magnitudes $(7,9)$. ANOVA was done and 3D plots were constructed to identify the consistency of the model and to evaluate the interactions between experimental variables.

Table 1: CCD design of the experimental factors along with their coded levels.

\begin{tabular}{clccccc}
\hline \multirow{2}{*}{ Factors } & \multirow{2}{*}{ Independent Variables } & \multicolumn{5}{c}{ Coded Levels } \\
\cline { 3 - 6 } & & -1.682 & -1 & 0 & 1 & 1.682 \\
\hline$x_{1}$ & Temperature (K) & 352.5 & 373 & 403 & 433 & 453.5 \\
$x_{2}$ & Concentration of oxidizing agent (M) & 12.7 & 40 & 80 & 120 & 147.3 \\
$x_{3}$ & Treatment time (min) & 12.7 & 40 & 80 & 120 & 147.3 \\
\hline
\end{tabular}

\section{RESULTS AND DISCUSSION}

The CCD method was employed to identify the effects of system variables on the TOC removal percentage and the relationship between them. Experimental and predicted results of TOC removal percentages are displayed in Table 2.

As clearly seen from Table 2, the highest experimental and predicted TOC removal percentage was obtained in run 20 and run 8 as $85.22 \%$ and $87.81 \%$, respectively, while the lowest experimental and predicted TOC removal percentage was obtained in run 11 as $22.51 \%$ and $22.63 \%$, respectively.

\section{Evaluation of the CCD modeling of mineralization of HCT}

ANOVA results of the CCD model of the mineralization of HCT were tabulated in Table 3. Statistical analysis, which is based on the evaluation of the Fisher's ' $F$ ' tests, and $p$-values of the model, is crucial to prove the significance of the employed model (7). $p$ and $F$ values of the model were found to be below 0.0001 and 62.88, respectively. The $P$-value of any model term is desired to be less than 0.05 to claim its significancy (37). In addition, possessing the highest $F$ value indicates a term as the most favourable term of the model. Thus, considering the $p$ and $F$ values of the model, one can say that the employed model is significant and it can be used to designate the effects of the experimental factors on the response, which is the TOC removal percentage. Furthermore, $x_{1}, x_{2}, x_{3}, x_{1} x_{2}, x_{1} x_{3}$, $x_{1}{ }^{2}$, and $x_{3}{ }^{2}$ are significant terms of the employed model. 
Table 2: Experimental and predicted results of the TOC removal efficiency.

\begin{tabular}{|c|c|c|c|c|c|c|c|}
\hline \multirow{2}{*}{ Run } & \multirow{2}{*}{$\begin{array}{c}\text { Temperature } \\
\text { (K) }\end{array}$} & \multirow{2}{*}{$\begin{array}{c}\text { Concentration } \\
\text { of oxidizing } \\
\text { agent }(M)\end{array}$} & \multirow{2}{*}{$\begin{array}{l}\text { Treatment } \\
\text { time (min) }\end{array}$} & \multicolumn{2}{|c|}{$\begin{array}{c}\text { TOC removal, } \\
\%\end{array}$} & \multirow{2}{*}{ Residual } & \multirow{2}{*}{$\begin{array}{l}\text { AD, } \\
\%\end{array}$} \\
\hline & & & & Exp. & $\begin{array}{l}\text { CCD } \\
\text { pre. }\end{array}$ & & \\
\hline 1 & $403(0)$ & $80(0)$ & $80(0)$ & 82.89 & 82.49 & 0.399 & 0.48 \\
\hline 2 & $403(0)$ & $80(0)$ & $80(0)$ & 80.94 & 82.49 & 1.551 & 1.92 \\
\hline 3 & $373(-1)$ & $120(+1)$ & $120(+1)$ & 82.06 & 83.78 & 1.723 & 2.10 \\
\hline 4 & $433(+1)$ & $40(-1)$ & $40(-1)$ & 84.01 & 80.34 & 3.675 & 4.37 \\
\hline 5 & $403(0)$ & $80(0)$ & $80(0)$ & 82.36 & 82.49 & 0.131 & 0.16 \\
\hline 6 & $373(-1)$ & $40(-1)$ & $120(+1)$ & 70.99 & 71.07 & 0.077 & 0.11 \\
\hline 7 & $352.5(-1.682)$ & $80(0)$ & $80(0)$ & 38.42 & 39.33 & 0.909 & 2.37 \\
\hline 8 & $403(0)$ & $147.3(+1.682)$ & $80(0)$ & 84.35 & 87.81 & 3.460 & 4.10 \\
\hline 9 & $373(-1)$ & $120(+1)$ & $40(-1)$ & 44.03 & 39.00 & 5.028 & 11.42 \\
\hline 10 & $433(+1)$ & $120(+1)$ & $40(-1)$ & 84.87 & 82.84 & 2.029 & 2.39 \\
\hline 11 & $373(-1)$ & $40(-1)$ & $40(-1)$ & 22.51 & 22.63 & 0.116 & 0.52 \\
\hline 12 & $433(+1)$ & $120(+1)$ & $120(+1)$ & 84.18 & 82.11 & 2.068 & 2.46 \\
\hline 13 & $403(0)$ & $80(0)$ & $80(0)$ & 84.12 & 82.49 & 1.629 & 1.94 \\
\hline 14 & $403(0)$ & $80(0)$ & $80(0)$ & 84.89 & 82.49 & 2.399 & 2.83 \\
\hline 15 & $453.5(+1.682)$ & $80(0)$ & $80(0)$ & 84.60 & 86.45 & 1.851 & 2.19 \\
\hline 16 & $403(0)$ & $80(0)$ & $80(0)$ & 80.22 & 82.49 & 2.271 & 2.83 \\
\hline 17 & $433(0)$ & $40(-1)$ & $120(+1)$ & 80.19 & 83.27 & 3.076 & 3.84 \\
\hline 18 & $403(0)$ & $80(0)$ & $12.7(-1.682)$ & 37.12 & 42.49 & 5.370 & 14.47 \\
\hline $\begin{array}{l}19 \\
20 \\
\end{array}$ & $\begin{array}{l}403(0) \\
403(0) \\
\end{array}$ & $\begin{array}{c}12.7(-1.682) \\
80(0)\end{array}$ & $\begin{array}{c}80(0) \\
147.3(+1.682)\end{array}$ & $\begin{array}{l}75.71 \\
85.22 \\
\end{array}$ & $\begin{array}{l}75.01 \\
82.61 \\
\end{array}$ & $\begin{array}{l}0.700 \\
2.610\end{array}$ & $\begin{array}{l}0.92 \\
3.06\end{array}$ \\
\hline
\end{tabular}

AD: Absolute difference between experimental and predicted values

Table 3: ANOVA results of the CCD model of the mineralization of HCT.

\begin{tabular}{cccccc}
\hline & \multicolumn{5}{c}{ TOC Removal } \\
\cline { 2 - 6 } Source & $\begin{array}{c}\text { Sum of } \\
\text { Squares }\end{array}$ & df & $\begin{array}{c}\text { Mean } \\
\text { Square }\end{array}$ & F Value & $\begin{array}{c}p \text {-value prob } \\
>\text { F }\end{array}$ \\
\hline Model & 7252.12 & 9 & 805.79 & 62.88 & $<0.0001$ \\
$\boldsymbol{X}_{\mathbf{1}}$ & 2680.36 & 1 & 2680.36 & 209.17 & $<0.0001$ \\
$\boldsymbol{X}_{\mathbf{2}}$ & 197.77 & 1 & 197.77 & 15.43 & 0.0028 \\
$\boldsymbol{X}_{\mathbf{3}}$ & 1942.95 & 1 & 1942.95 & 151.63 & $<0.0001$ \\
$\boldsymbol{X}_{\mathbf{1}} \boldsymbol{X}_{\mathbf{2}}$ & 96.19 & 1 & 96.19 & 7.51 & 0.0208 \\
$\boldsymbol{X}_{\mathbf{1}} \boldsymbol{X}_{\mathbf{3}}$ & 1035.58 & 1 & 1035.58 & 80.82 & $<0.0001$ \\
$\boldsymbol{X}_{\mathbf{2}} \boldsymbol{X}_{\mathbf{3}}$ & 6.70 & 1 & 6.70 & 0.52 & 0.4863 \\
$\boldsymbol{X}_{\mathbf{1}}{ }^{2}$ & 692.08 & 1 & 692.08 & 54.01 & $<0.0001$ \\
$\boldsymbol{X}_{\mathbf{2}}{ }^{2}$ & 2.10 & 1 & 2.10 & 0.16 & 0.6939 \\
$\boldsymbol{X}_{\mathbf{3}}{ }^{2}$ & 716.30 & 1 & 716.30 & 55.90 & $<0.0001$ \\
Residual & 128.14 & 10 & 12.81 & & 0.0264 \\
Lack of Fit & 112.03 & 5 & 22.41 & 6.95 & \\
Pure Error & 16.11 & 5 & 3.22 & & \\
\hline & & & & & \\
\hline
\end{tabular}

$Y=14.01 x_{1}+3.81 x_{2}+11.93 x_{3}-3.47 x_{1} x_{2}-11.38 x_{1} x_{3}-0.91 x_{2} x_{3}-6.93 x_{1}^{2}-0.38 x_{2}^{2}-7.05 x_{3}^{2}+82.49$ (Eq. $1)$. 
The predicted TOC removal percentages of all runs were obtained by employing CCD. The second-order polynomial equation (Eq. 1) was used for this purpose. Also, using Eq. 1 is a practical way for predicting the response of the system for given levels of system factors. In addition, the coefficient of the coded factors of the equation shows the level of effectiveness of each factor on the TOC removal percentages. Thus, it is clearly seen that temperature is the most effective variable on the TOC removal rates followed by treatment time, while the quadratic effect of the $\mathrm{H}_{2} \mathrm{O}_{2}$ concentration remains negligible.

Table 4: Regression coefficients of the CCD model.

\begin{tabular}{llll}
\hline \multicolumn{4}{c}{ Regression coefficients } \\
\hline Standard Deviation & 3.58 & $\mathbf{R}^{\mathbf{2}}$ & 0.9826 \\
Mean & 72.68 & Adjusted $\mathbf{R}^{\mathbf{2}}$ & 0.9670 \\
C.V. \% & 4.92 & Predicted $\mathbf{R}^{\mathbf{2}}$ & 0.8768 \\
PRESS & 909.56 & Adequate Precision & 25.752 \\
\hline
\end{tabular}

The regression coefficients of a model show its reliability. Table 4 demonstrates the regression coefficients of the employed CCD model. The obtained predicted residual sum of squares (PRESS) value of 909.56 shows that the model adapts each point in the design. The adequate precision value of 25.752 verifies that the model can be applied to navigate the design space (7). Also, the conformity of the model was provided based on the $R^{2}$ value of 0.9826 . The adjusted $R^{2}$ value of 0.9670 represents the amount of variation around the mean. The reasonable agreement of the $R^{2}$ value with adjusted $R^{2}$ indicate $a$ high correlation level between experimental and predicted values. Further, Figure 2, which depicts the correlation between actual (experimental) and predicted TOC removal values, supports this accordance. Closeness of colored points to the linear line demonstrates the conformity of experimental and predicted values. Thus, Figure 2 shows that both actual and predicted points of the applied method match each other.

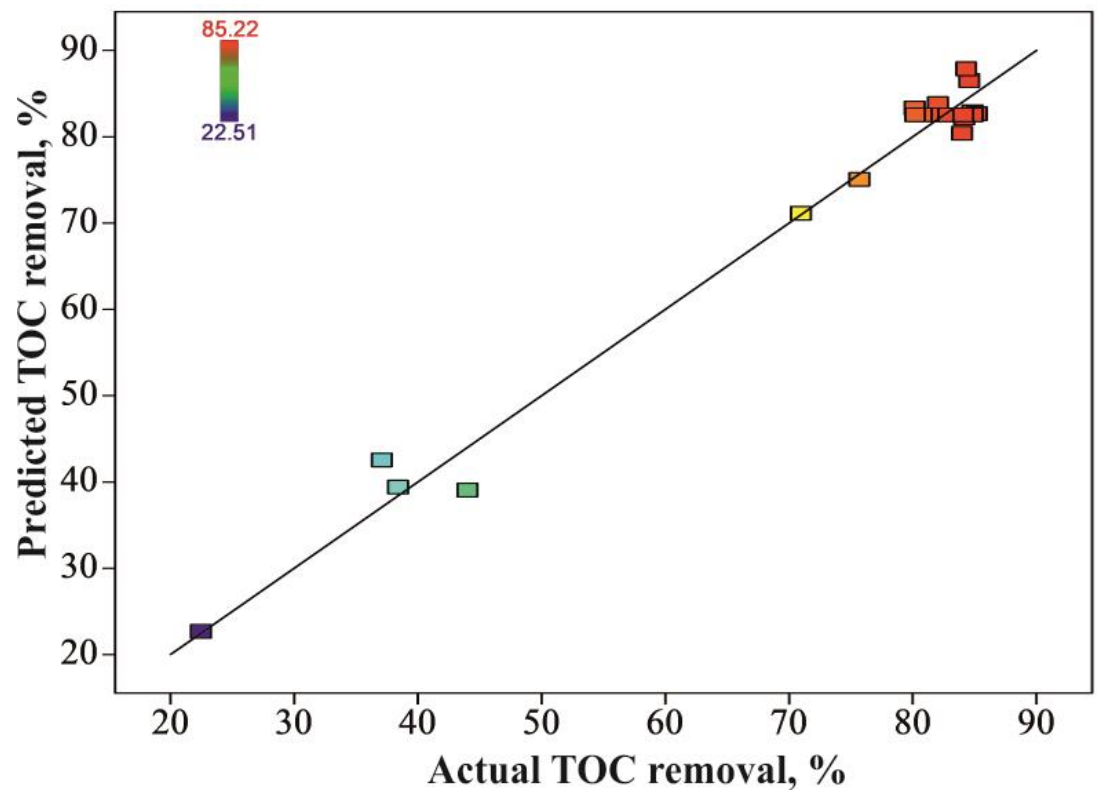

Figure 2: Correlation between actual and predicted values of the TOC removal rates.

Figure 3 shows the cube plot of CCD model of the TOC removal. It is feasible to predict the response in any case that consists of three experimental factors in the working range by using Figure 3. In addition, the evaluation of the further experiments and estimation of the experimental conditions can be performed by the aid of Figure 3. It can be seen from this figure that $83.78 \%$ of
TOC removal percentage can be obtained at the highest level of treatment time and $\mathrm{H}_{2} \mathrm{O}_{2}$ concentration but at the lowest level of temperature. Moreover, almost the same value of TOC removal percentage can be obtained ( 83.26 $\%$ ) by increasing the temperature and treatment time to their highest value and decreasing the concentration of $\mathrm{H}_{2} \mathrm{O}_{2}$ to its lowest value. 




(a)

Figure 3: Cube plot of the model.

Binary effects of experimental variables on the response can be demonstrated by using threedimensional surface plots. Figure 4 shows the binary effects of $\mathrm{H}_{2} \mathrm{O}_{2}$ concentration and temperature on the TOC removal at the fixed treatment time of $50 \mathrm{~min}$. It is clearly seen that the combined effect of temperature and $\mathrm{H}_{2} \mathrm{O}_{2}$ concentration increases TOC removal percentages, especially above $413 \mathrm{~K}$, at the fixed treatment time of $50 \mathrm{~min}$. Moreover, $50 \mathrm{~min}$ and above treatment times are quite sufficient for formation of hydroxyl and other radicals at above medium levels of temperature and $\mathrm{H}_{2} \mathrm{O}_{2}$ concentration. Thus, when the reaction medium contains an appropriate amount of $\mathrm{H}_{2} \mathrm{O}_{2}$, temperature plays the major role in providing these radicals and elevating the mineralization percentage of $\mathrm{HCT}$. The role of $\mathrm{H}_{2} \mathrm{O}_{2}$ concentration remains minor considering the role of temperature in the above-mentioned conditions. While the effect of temperature increases in its high levels, the effect of $\mathrm{H}_{2} \mathrm{O}_{2}$ concentration gains importance in the lower level of temperature in the fixed 50 min of treatment time. For example, $69.58 \%$ of TOC removal increases to $85.19 \%$ by elevating the temperature from $403 \mathrm{~K}$ to $433 \mathrm{~K}$ at the fixed treatment time of 50 min and $\mathrm{H}_{2} \mathrm{O}_{2}$ concentration of $80 \mathrm{mM}$. However, only about 2 $\%$ increase is seen in the $83.78 \%$ of TOC removal value by increasing $\mathrm{H}_{2} \mathrm{O}_{2}$ concentration from 40 $\mathrm{mM}$ to $120 \mathrm{mM}$ at the fixed treatment time of 50 min and $433 \mathrm{~K}$ of temperature. Moreover, when the same enhancement was applied at the same treatment time, about $9 \%$ and $16 \%$ of enhancement are observed at $403 \mathrm{~K}$ and $373 \mathrm{~K}$, respectively.

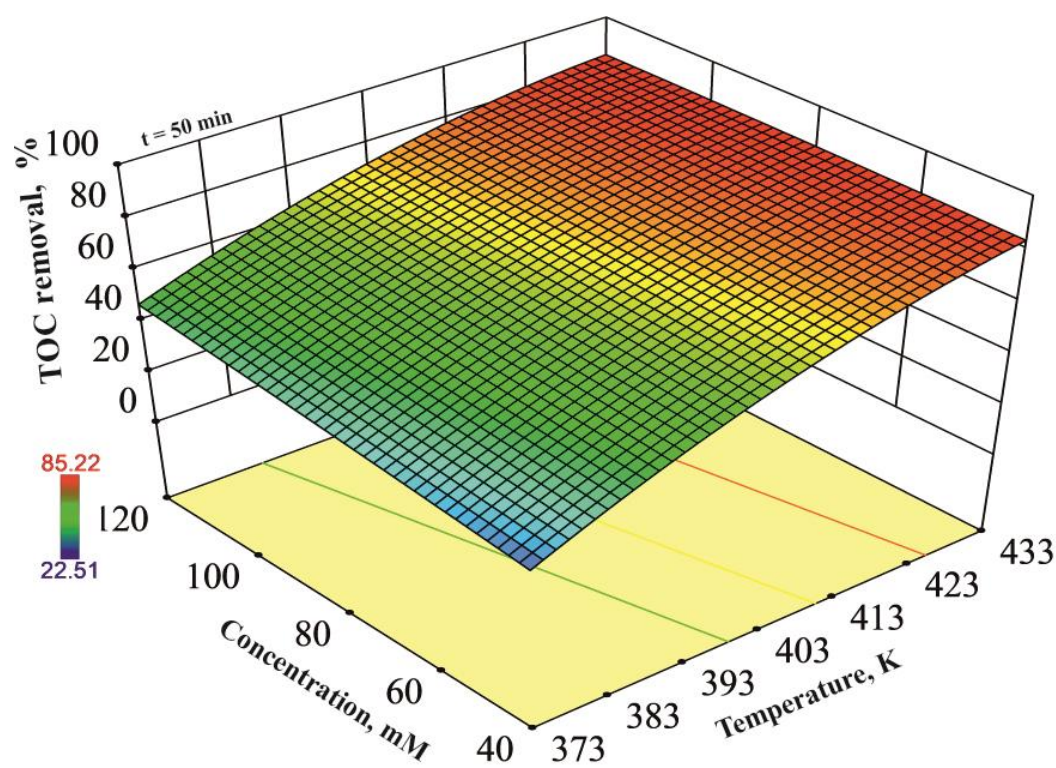

Figure 4: Binary effects of $\mathrm{H}_{2} \mathrm{O}_{2}$ concentration and temperature on the TOC removal at fixed treatment time of $50 \mathrm{~min}$. 
The combined effect of treatment time and temperature on the TOC removal at the fixed $\mathrm{H}_{2} \mathrm{O}_{2}$ concentration of $40 \mathrm{mM}$ is shown in Figure 5. This effect is quite noteworthy, especially at above the medium level of both temperature and treatment time at the fixed $\mathrm{H}_{2} \mathrm{O}_{2}$ concentration of $40 \mathrm{mM}$.

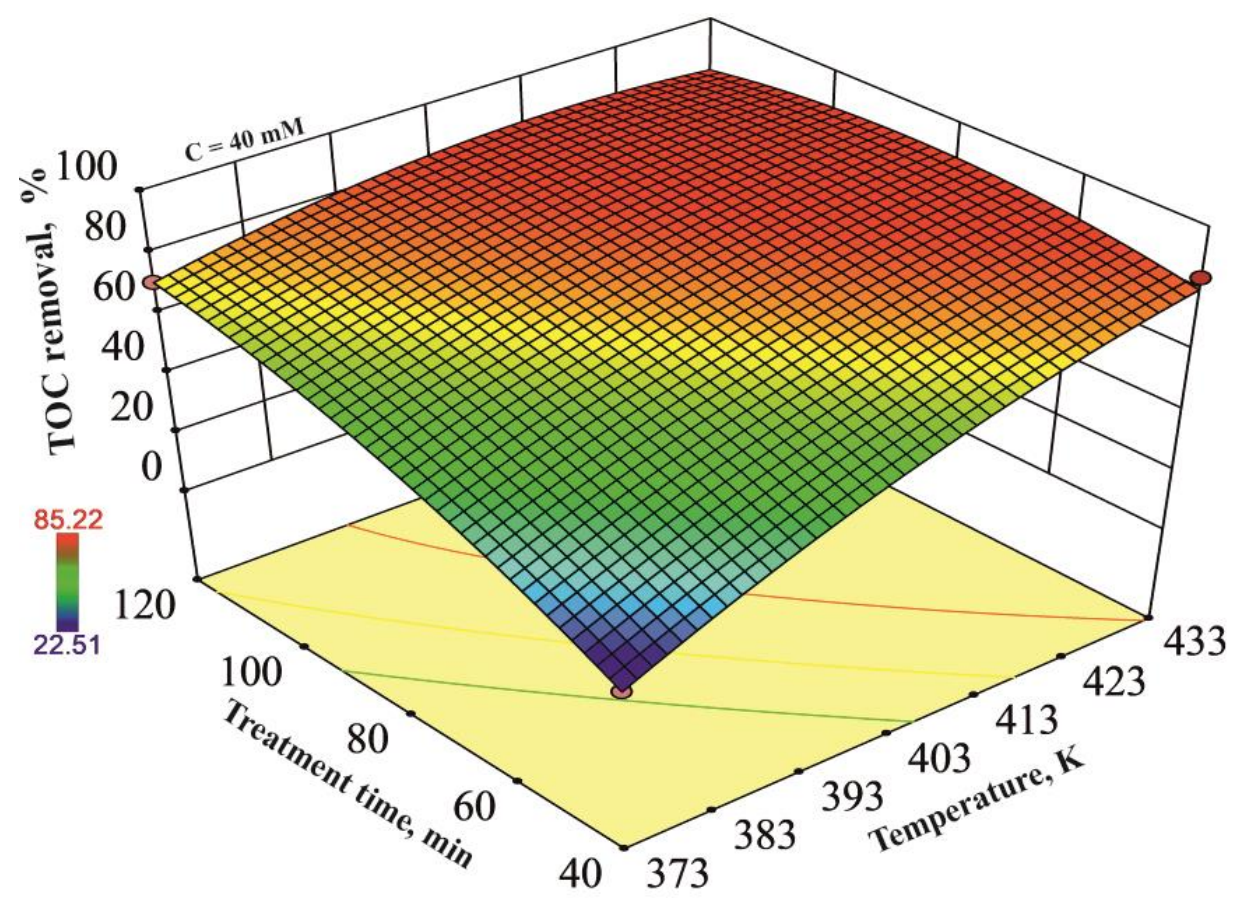

Figure 5: Binary effects of treatment time and temperature on the TOC removal at fixed $\mathrm{H}_{2} \mathrm{O}_{2}$ concentration of $40 \mathrm{mM}$.

Alternatively, short treatment time-high temperature and long treatment time-low temperature conditions provide elevated TOC removal rates at the fixed $\mathrm{H}_{2} \mathrm{O}_{2}$ concentration of $40 \mathrm{mM}$, according to Figure 5 . Based on these results, one can say that adequate free radicals might be formed by keeping treatment time or temperature at specific values. For instance, to obtain $80.34 \%$ of TOC removal, $433 \mathrm{~K}$ of temperature and $40 \mathrm{~min}$ of treatment time is required at the fixed $\mathrm{H}_{2} \mathrm{O}_{2}$ concentration of 40 $\mathrm{mM}$. The same efficiency can be obtained at 390.5 $\mathrm{K}$ of temperature and $120 \mathrm{~min}$ of treatment time at the same $\mathrm{H}_{2} \mathrm{O}_{2}$ concentration.

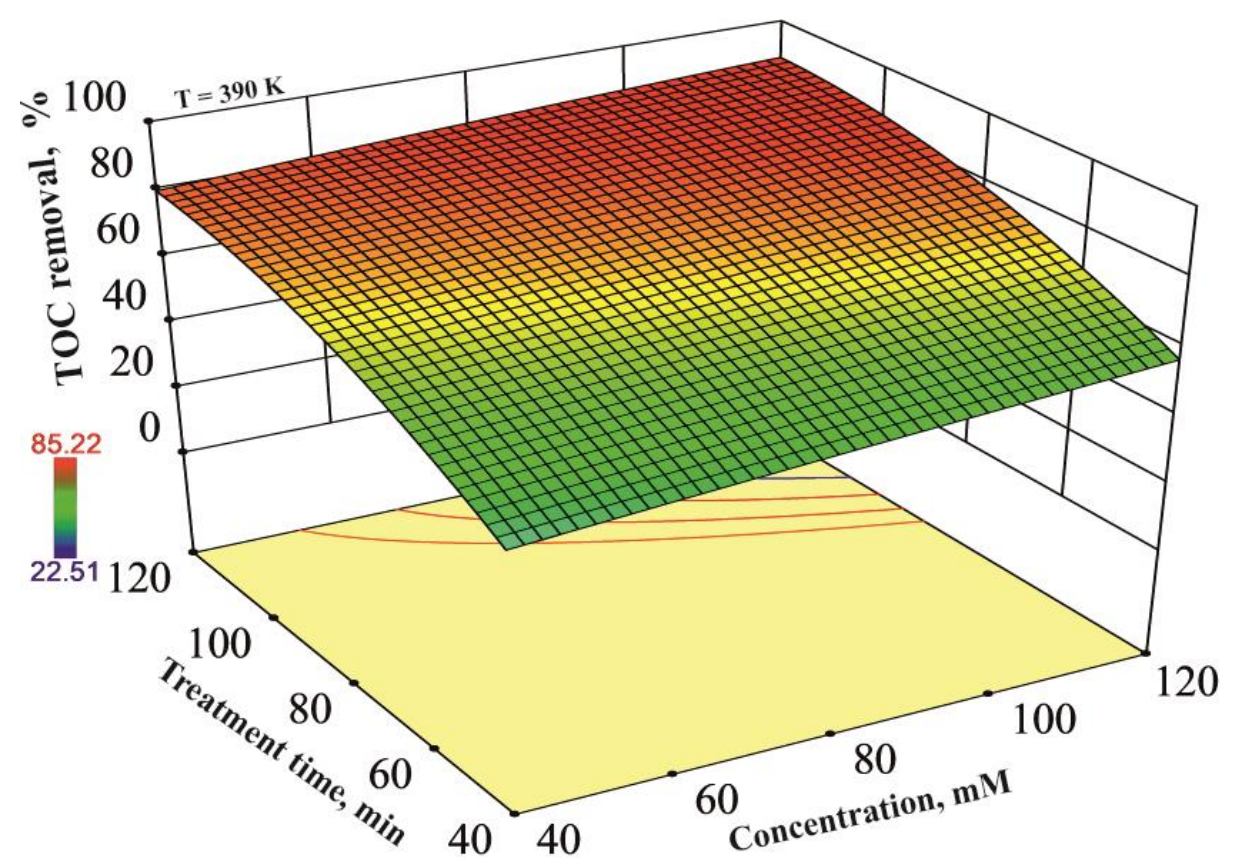

Figure 6: Binary effects of treatment time and $\mathrm{H}_{2} \mathrm{O}_{2}$ concentration on the TOC removal at the fixed temperature of $390 \mathrm{~K}$. 
Binary effects of treatment time and $\mathrm{H}_{2} \mathrm{O}_{2}$ concentration on the TOC removal at the fixed temperature of $390 \mathrm{~K}$ are demonstrated in Figure 6 . This figure shows that, while moderate TOC removal percentages can be obtained at low levels of $\mathrm{H}_{2} \mathrm{O}_{2}$ concentration and treatment time at the fixed temperature of $390 \mathrm{~K}$, the treatment time must be increased to obtain high TOC removal percentages. Further, increasing the $\mathrm{H}_{2} \mathrm{O}_{2}$ concentration at moderate and upper levels of treatment time at the fixed temperature of 390 $\mathrm{K}$ only has little influence on the TOC removal percentages. It may be attributed to the fact that, while the role of $\mathrm{H}_{2} \mathrm{O}_{2}$ concentration is crucial in the mineralization of $\mathrm{HCT}$, increasing the $\mathrm{H}_{2} \mathrm{O}_{2}$ concentration above a specific level does not directly elevate degradation rates due to possible self-quenching of free radicals present in the reaction medium (7). According to Figure 6, this method should be regarded as superior to the conventional methods in terms of achieving the same efficiency with different application conditions. Thus, the possibility of achieving high efficiency of TOC removal of HCT at long treatment time and low temperature or at short treatment time and high temperature provides important advantages in reducing the operating costs on the industrial scale (large scale applications).

\section{CONCLUSIONS}

Mineralization of HCT was effectively achieved by using subcritical water oxidation as an applicable, efficient and environmentally friendly method, and by using $\mathrm{H}_{2} \mathrm{O}_{2}$ as a green oxidizing agent. Subcritical water favoured the formation of free radicals, and in the presence of $\mathrm{H}_{2} \mathrm{O}_{2}$, at an adequate treatment time. Thus, it can be said that on the basis of the obtained results, subcritical water and $\mathrm{H}_{2} \mathrm{O}_{2}$ have synergetic effects on the TOC removal of HCT. High TOC removal rate $(85.22 \%)$ proved the reliability of this method as well as its applicability in the mineralization process of similar contaminants. Moreover, the CCD method was performed and the interaction of experimental variables as well as their effects on the response was evaluated. Temperature, followed by treatment time, were found to be effective experimental factors on the efficiency of the method. Also, the obtained high TOC removal rates in the short treatment time show that the applied method is a time-saving method.

\section{REFERENCES}

1. Ahmed MB, Kumer A, Islam M, Islam TSA. The Photochemical Degradation (PCD) of Nitrobenzene (NB) using UV Light and Fenton Reagent Under Various Conditions. Journal of the Turkish Chemical Society, Section A: Chemistry. 2018;5(2):803-818.

2. Lima DRS, Tonucci MC, Libânio M, Aquino SFD. Pharmaceuticals and etrndocrine disrupting compounds in Brazilian waters: occurrence and removal techniques. Engenharia Sanitaria E Ambiental. 2017 Nov-Dec;22(6):1043-1054.

3. Li Z, Sobek A, Radke M. Fate of pharmaceuticals and their transformation products in four small European rivers receiving treated wastewater. Environmental Science \& Technology. 2016 Jun;50(11):5614-5621.

4. López-Serna $R$, Jurado $A$, Vázquez-Suñé $E$, Carrera J, Petrović M, Barceló, D. Occurrence of 95 pharmaceuticals and transformation products in urban groundwaters underlying the metropolis of Barcelona, Spain. Environmental Pollution. 2013 Mar; 174:305-315.

5. Benotti MJ, Trenholm RA, Vanderford $B J$, Holady JC, Stanford BD, Snyder SA. Pharmaceuticals and endocrine disrupting compounds in US drinking water. Environmental Science \& Technology. 2009 Feb;43(3):597-603.

6. Yabalak E, Görmez Ö, Gizir AM. Subcritical water oxidation of propham by $\mathrm{H}_{2} \mathrm{O}_{2}$ using response surface methodology (RSM). Journal of Environmental Science and Health, Part B. $2018 ; 53(5): 334-339$.

7. Yabalak, E. Degradation of ticarcillin by subcritial water oxidation method: Application of response surface methodology and artificial neural network modeling. Journal of Environmental Science and Health, Part A. 2018. https://doi.org/10.1080/10934529.2018.147102 3.

8. Emire Z, Yabalak E, Görmez Ö, Gizir AM. Solubility and degradation of paracetamol in subcritical water. Journal of the Serbian Chemical Society. 2017;82(1):99-106.

9. Yabalak E, Adiguzel SK, Adiguzel AO, Ergene RS, Tuncer M, Gizir AM. Application of response surface methodology for the optimization of oxacillin degradation by subcritical water oxidation using $\mathrm{H}_{2} \mathrm{O}_{2}$ : genotoxicity and antimicrobial activity analysis of treated samples. Desalination and Water Water Treatment. 2017 Jun;81:186-198.

10. Turabik M, Oturan N, Gözmen B, Oturan MA. Efficient removal of insecticide "imidacloprid" from water by electrochemical advanced oxidation processes. Environmental Science and Pollution Research. 2014 Jul;21(14):8387-8397.

11. Hasan N, Moon GH, Park J, Park J, Kim J. Visible light-induced degradation of sulfa drugs on pure $\mathrm{TiO}_{2}$ through ligand-to-metal charge transfer. Separation and Purification Technology. 2018 Sep;203:242-250.

12. Giahi M. Photocatalytic degradation of diclofenac sodium in aqueous solution using $\mathrm{N}, \mathrm{S}$, 
and C-doped ZnO. Russian Journal of Applied Chemistry. 2015 Dec;88(12):2044-2049.

13. Ji $Y$, Wang $L$, Jiang $M$, Yang $Y$, Yang $P, L u ~ J$, Ferronato C, Chovelon, J-M. Ferrous-activated peroxymonosulfate oxidation of antimicrobial agent sulfaquinoxaline and structurally related compounds in aqueous solution: kinetics, products, and transformation pathways. Environmental Science and Pollution Research. 2017 Aug;24(24):19535-19545.

14. Altamimi MA, Elzayat EM, Alhowyan $A A$, Alshehri S, Shakeel F. Effect of $\beta$-cyclodextrin and different surfactants on solubility, stability, and permeability of hydrochlorothiazide. Journal of Molecular Liquids. 2018 Jan;250:323-328.

15. Phechkrajang CM, Quynh PTN, Suntornsuk L. Forced Degradation Studies of Candesartan Cilexetil and Hydrochlorothiazide Using a Validated Stability-Indicating HPLC-UV Method. Pharmaceutical Chemistry Journal. 2017 Aug;51(5):416-424.

16. Armaković SJ, Armaković S, Četojević-Simin DD, Šibul F, Abramović BF. Photocatalytic degradation of 4-amino-6-chlorobenzene-1,3disulfonamide stable hydrolysis product of hydrochlorothiazide: Detection of intermediates and their toxicity. Environmental Pollution. 2018 Feb;233:916-924.

17. Petrović M, Škrbić B, Živančev J, FerrandoCliment L, Barcelo D. Determination of 81 pharmaceutical drugs by high performance liquid chromatography coupled to mass spectrometry with hybrid triple quadrupole-linear ion trap in different types of water in Serbia. Science of the Total Environment. 2014 Jan;468:415-428.

18. Real FJ, Acero JL, Benitez FJ, Roldán G, Fernández LC. Oxidation of hydrochlorothiazide by UV radiation, hydroxyl radicals and ozone: Kinetics and elimination from water systems. Chemical Engineering Journal. 2010 May; $160(1): 72-78$.

19. Mahajan AA, Thaker AK, Mohanraj K. LC, LCMS/MS studies for the identification and characterization of degradation products of hydrochlorothiazide and establishment of mechanistic approach towards degradation. Journal of the Brazilian Chemical Society. 2012 Mar;23(3):445-452.

20. Márquez G, Rodríguez EM, Beltrán FJ, Álvarez PM. Solar photocatalytic ozonation of a mixture of pharmaceutical compounds in water. Chemosphere. 2014 Oct:113;71-78.

21. Contreras N, Vidal J, Berríos C, Villegas L, Salazar R. Degradation of antihypertensive hydrochlorothiazide in water from pharmaceutical formulations by electro-oxidation using a BDD anode. International Journal of Electrochemical Science. 2015 Sep;10(11):9269-9285.

22. Paiva VAB, Paniagua CES, Ricardo IA, Gonçalves BR, Martins SP, Daniel D, Machado AEH, Trovó AG. Simultaneous degradation of pharmaceuticals by classic and modified photoFenton process. Journal of Environmental Chemical Engineering. 2018 Feb;6(1):10861092.

23. Armaković SJ, Armaković S, Četojević-Simin DD, Šibul F, Abramović BF. Photocatalytic degradation of 4-amino-6-chlorobenzene-1, 3disulfonamide stable hydrolysis product of hydrochlorothiazide: Detection of intermediates and their toxicity. Environmental Pollution. 2018 Feb;233:916-924.

24. Phechkrajang CM, Quynh PTN, Suntornsuk L. Forced Degradation Studies of Candesartan Cilexetil and Hydrochlorothiazide Using a Validated Stability-Indicating HPLC-UV Method. Pharmaceutical Chemistry Journal. 2017 Aug;51(5):416-424.

25. Borowska E, Bourgin M, Hollender J, Kienle C, McArdell CS, Von Gunten U. Oxidation of cetirizine, fexofenadine and hydrochlorothiazide during ozonation: Kinetics and formation of transformation products. Water Research. 2016 May;94:350-362.

26. Yabalak E, Gizir MA. Subcritical and supercritical fluid extraction of heavy metals from sand and sewage sludge. Journal of the Serbian Chemical Society. 2013;78(7):1013-1022.

27. Yabalak E, Görmez Ö, Gözmen B, Gizir AM. The solubility of sebacic acid in subcritical water using the response surface methodology. International Journal of Industrial Chemistry. 2015 Mar;6(1):23-29.

28. Nural Y, Gemili M, Yabalak E, De Coen L, Ulger M. Green synthesis of highly functionalized octahydropyrrolo[3,4-c]pyrrole derivatives using subcritical water, and their anti(myco)bacterial and activity. Arkivoc. 2018;2018(5):51-64.

29. Demirkol O, Akbaflar D, Giray ES. Clean and efficient synthesis of flavanone in sub-critical water. The Journal of Supercritical Fluids. 2013 Sep; $81: 217-220$.

30. Ribeiro RS, Silva AM, Figueiredo JL, Faria JL, Gomes HT. Catalytic wet peroxide oxidation: a route towards the application of hybrid magnetic carbon nanocomposites for the degradation of organic pollutants. A review. Applied Catalysis B: Environmental. 2016 Jun;187:428-460.

31. Fu J, Kyzas GZ. Wet air oxidation for the decolorization of dye wastewater: An overview of 
the last two decades. Chinese Journal of Catalysis. 2014 Jan;35(1):1-7.

32. Singh KP, Gupta $S$, Singh AK, Sinha $S$. Optimizing adsorption of crystal violet dye from water by magnetic nanocomposite using response surface modeling approach. Journal of Hazardous Materials. 2011 Feb;186(2-3):1462-1473.

33. Abdullah $A Z$, Salamatinia $B$, Kamaruddin $A H$. Application of response surface methodology for the optimization of $\mathrm{NaOH}$ treatment on oil palm frond towards improvement in the sorption of heavy metals. Desalination. 2009 Aug;244(13):227-238.

34. Llop A, Pocurull E, Borrull F. Evaluation of the removal of pollutants from petrochemical wastewater using a membrane bioreactor treatment plant. Water, Air, and Soil Pollution. 2009 Feb;197(1-4):349-359.
35. Krowiak AW, Chojnacka K, Podstawczyk D, Dawiec A, Pokomeda K. Application of response surface methodology and artificial neural network methods in modelling and optimization of biosorption process. Bioresource Technology. 2014 May; 160:150-160.

36. Pilkington JL, Preston C, Gomes RL. Comparison of response surface methodology (RSM) and artificial neural networks (ANN) towards efficient extraction of artemisinin from Artemisia annua. Industrial Crops and Products. 2014 Jul;58:15-24.

37. Yabalak E, Görmez Ö, Sönmez Gözmen B. Degradation, dephenolisation and dearomatisation of olive mill wastewater by subcritical water oxidation method using hydrogen peroxide: Application of multi-response central composite design. Journal of the Serbian Chemical Society. 2018;83:489-502. 